\title{
Chest Pain and Exercise Induced Ischemia with Angiographically Insignificant Coronary Arterial Disease: Clinical Presentation and Follow-Up
}

\author{
Md. Khurshed Ahmed ${ }^{1}$, Mohammad Salman², Md. Ashraf Uddin Sultan ${ }^{1}$, Md. Abu Siddique ${ }^{1}$, \\ KMHS Sirajul Haque1, Md. Harisul Hoque', Md. Mizanur Rahman Khan ${ }^{3}$, Mohammad Ferdous Ur Rahaman ${ }^{3}$, \\ Shahed Mohammed Anwar4 \\ ${ }^{1}$ Department of Cardiology, Bangabandhu Sheikh Mujib Medical University (BSMMU), Shahbag, Dhaka. \\ ${ }^{2}$ Anwer Khan Modern Medical College, Dhanmondi, Dhaka. \\ ${ }^{3}$ Department of Medicine, Bangabandhu Sheikh Mujib Medical University (BSMMU), Shahbag, Dhaka. \\ ${ }^{4}$ Department of Surgery, University of Science and Technology, Foy's Lake, Chittagong. \\ Address for correspondence \\ Dr. Md. Khurshed Ahmed, Assistant Professor, Department of Cardiology, Bangabandhu Sheikh Mujib Medical University, Dhaka, \\ Bangladesh. \\ e mail-drmdsalman@gmail.com
}

\begin{abstract}
Angiography of patients with typical chest pain reveals normal epicardial coronary arteries in about $15-20 \%$. ECG changes suggestive of myocardial ischemia during exercise also can be demonstrated in this subset of the patients. Total 58 patients (42 females) with mean age $42 \pm 7$ years who were undergoing coronary angiogram in the Department of Cardiology, University Cardiac Center, Bangabandhu Sheikh Mujib Medical University, Dhaka, Bangladesh from January 2005 to December 2009 were evaluated. The patients were recruited on the basis of presence of history of chest pain, with normal resting ECG and ischemia like ECG changes during exercise stress test. 32.8\% patients had hypertension and $15.5 \%$ were diabetics, $19.0 \%$ had dyslipidemia and $6.9 \%$ had family history of ischemic heart disease. All the patients were having positive exercise stress test. Angiographic findings showed luminal irregularities in $29.3 \%$ patients, 15.5\% patients had luminal stenosis less than $30 \%$ and rest had normal coronary angiogram. Follow up of the patients after one and six months of angiogram was done. After one month $63.8 \%$ patients remained symptomatic and after six months $63.3 \%$ patients remained symptomatic despite maximum medical management. The pathophysiology and appropriate management of this subset of the patients still remained a challenge for physicians. Optimum management of cardiovascular risk factors is very important issue in this group of patients.
\end{abstract}

Key words: Angiography, Epicardial coronary arteries, Exercise stress test, Cardiovascular risk factors.

\section{Introduction}

The typical angina pectoris and a positive stress test in the presence of angiographically normal coronary arteries is found in about $15-20 \%$ of patients undergoing cardiac catheterization. ${ }^{1-4}$ In about $50 \%$ of these patients anginal pain is attributed to changes in coronary microvasculature. $^{5-7}$ We usually classify them as Syndrome $\mathrm{X}$ and Microvascular Angina. Syndrome $\mathrm{X}$ is defined by a typical angina pectoris with normal or near normal ( $<40 \%$ stenosis $)$ coronary angiogram with or without ECG change or atypical angina pectoris with normal or near normal coronary angiogram plus a positive non-invasive test (exercise tolerance test or myocardial perfusion scan) with or without ECG changes. 8,9 Patients with coronary artery spasm (Prinzmetal's or variant angina), left ventricular hypertrophy, systemic hypertension, and valvular heart disease are not included in this syndrome. ${ }^{10}$ The term "Microvascular
Angina" (MVA) includes all such patients with coronary microcirculatory derangements but with normal coronary angiograms irrespective of the presence or absence of exercise- induced ST segment depression. ${ }^{11}$

The exact pathophysiological mechanisms underlying these conditions are not well understood, and many mechanisms for the chest pain have been suggested. In some studies, microvascular dysfunction has been proposed as the cause 12-14 whereas in others, metabolic abnormalities, such as net myocardial lactate production have been demonstrated. ${ }^{\text {15-19 }}$ Noninvasive imaging has been used to determine whether ischemia is present or not. Controversial findings have been reported regarding left ventricular function in MVA. Though regional wall motion abnormalities have been reported using stress nuclear techniques, two dimensional echocardiography has not disclosed any segmental contractile dysfunction. 20 
The remaining $50 \%$ of these patients have non cardiac causes of chest pain, such as gastro-esophageal reflux, hernia, or degeneration of the skeletal system. Differential diagnosis between cardiac and non cardiac origin often is difficult but necessary for initiation of the appropriate therapy. In fact, a substantial number of these patients continue having chest pain after angiography and will undergo repeated coronary catheterizations thereafter. ${ }^{21}$

In this study we analyzed and followed up consecutively this subset of the patients in our center.

\section{Materials and methods}

This prospective observational study was conducted in the Department of Cardiology, University Cardiac Center, Bangabandhu Sheikh Mujib Medical University, Dhaka, Bangladesh from January 2005 to December 2009. Total 58 patients (42 females) with mean age, $42 \pm 7$ years; range, 3556 years, who were undergoing coronary angiogram recruited on the basis of the following criteria: a history of chest pain, with normal resting ECG or nonspecific disturbances of ventricular repolarization (flat and low-voltage negative $\mathrm{T}$ waves) and ischemia like ECG changes during exercise stress test (horizontal or down sloping ST segment depression $\geq 0.1 \mathrm{mV}$ of the baseline value 0.08 seconds after the Jpoint). All patients had a normal resting echocardiogram. Hypertension was defined as a blood pressure $>140 / 90 \mathrm{~mm}$ Hg. Diabetes mellitus was defined as fasting blood glucose level $\geq 7.0 \mathrm{mmol} / \mathrm{l}$ or patient is receiving oral hypoglycemic drugs or insulin. Dyslipidemia was defined as total cholesterol $\geq 200 \mathrm{mg} / \mathrm{dl}$, low density lipoprotein (LDL) $\geq 130$ $\mathrm{mg} / \mathrm{dl}$ and high density lipoprotein (HDL) $\geq 40 \mathrm{mg} / \mathrm{dl}$ in male $\geq 50 \mathrm{mg} / \mathrm{dl}$ in female. Mitral valve prolapse, primary myocardial disease, or any other valvular or congenital heart disease patients were excluded from the study. A period of pharmacological washout of at least 72 hours was allowed before the stress test in the patients who were taking $\beta$ blockers, non-dihydropyridine $\mathrm{Ca}^{++}$channel blockers, or nitrate. The stress test was always performed within the 3 weeks preceeding of the coronary angiogram. Each subject was informed of the investigative nature of the study, and written consent was obtained before entry. After the angiogram all the patients were prescribed low dose aspirin, nitrate, $\beta$ blocker and statin and followed up after one month and six months of angiogram. In follow up patients were interviewed about any change in their symptoms and a 12 lead ECG was done.

\section{Statistical analysis}

Statistical analysis was done by SPSS (Statistical Package for Social Science) software for windows version 12.0. Data were expressed in number, percent or mean \pm SD.

\section{Results}

\section{Demographic and clinical characteristics}

The demographic and clinical characteristics of 58 cases are listed in Table 1. Total 58 consecutive patients [42 (72.4\%) women and $16(27.6 \%)$ men] were included in the study. Mean age was $42 \pm 07$ years and range, 35 to 56 years. BMI was 25.73.9 All were having angina pectoris (Canadian Cardiovascular Society, CCS class III or IV). 19 (32.8\%) patients had hypertension and $9(15.5 \%)$ were diabetics. 11 $(19.0 \%)$ had dyslipidemia. 4 (6.9\%) had family history of ischemic heart disease. All the patients were having positive exercise stress test.

Table 1. Demographic and clinical characteristics of the patients $(\mathrm{N}=\mathbf{5 8})$.

\begin{tabular}{lcc}
\hline Variables & $\begin{array}{c}\text { Numbers or } \\
\text { MeantSD }\end{array}$ & $\begin{array}{c}\text { Percent } \\
(\%)\end{array}$ \\
\hline Age & $42 \pm 07$ & - \\
Female & 42 & $(72.4 \%)$ \\
Male & 16 & $(27.6 \%)$ \\
BMI & $25.7 \pm 3.9$ & - \\
Hypertension & 18 & $(32.8 \%)$ \\
Diabeies mellitus & 09 & $(15.5 \%)$ \\
Dyblipidemia & 11 & $(19.0 \%)$ \\
$\begin{array}{l}\text { Family history of isehemic heart } \\
\text { discase }\end{array}$ & 4 & $(6.9 \%)$ \\
\hline
\end{tabular}

All the data are in total number, percent or mean \pm standard deviation.

Figure 1 shows the ECG findings of the subjects. Nonspecific ST-T changes were found among the $64 \%$ subjects whereas it was normal among $36 \%$ of subjects.

\section{ECG findings among the patients}

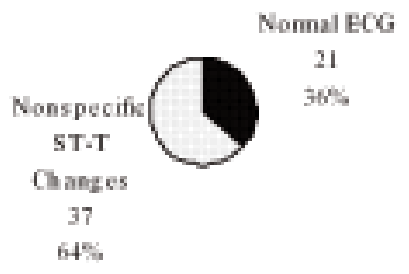

Figure 1. Frequency distribution of the ECG findings among the patients

Angiographic findings showed luminal irregularities in 17 (29.3\%) patients, $9(15.5 \%)$ patients were having luminal stenosis less than $30 \%$ and remaining patients have normal coronary angiogram. (Table 2 \& Figure 2) 
Table 2. Angiographic findings of the patients $(\mathrm{N}=58)$

\begin{tabular}{lcc}
\hline Angiographic findings & Numbers & Pereent (\%) \\
\hline Luminal stenosis $\leq 30 \%$ & 9 & 15.5 \\
Luminal irregularities & 17 & 29.3 \\
Normal & 32 & 55.2 \\
\hline
\end{tabular}

All the data are in total number and percent.

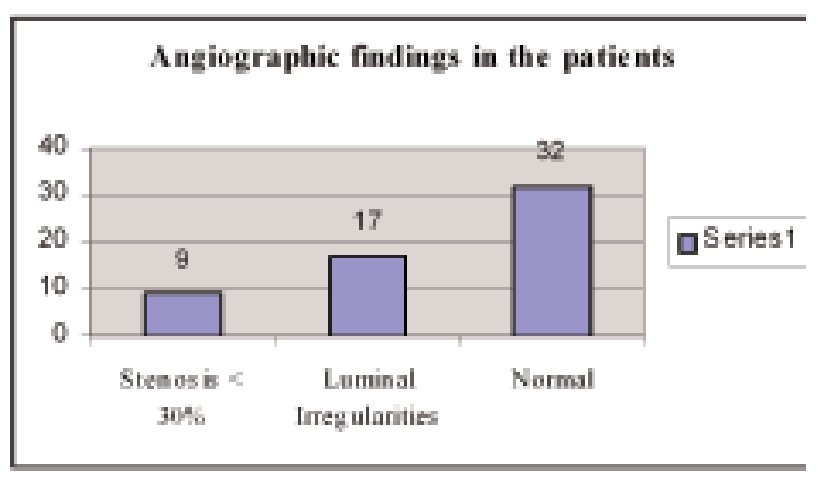

Figure 2. Angiographic findings of the patients $(\mathrm{N}=58)$

Table 3 shows the follow up data of the patients after one and six months of angiogram. After one month $63.8 \%$ patients remain symptomatic and after six months $63.3 \%$ patients remain symptomatic though $15.5 \%$ cases were dropped out during six months follow up.

Table 3. Follow up data of the patients.

\begin{tabular}{|c|c|c|}
\hline Number of the patients & Symptoms persisted & Symptoms amelierated \\
\hline \multicolumn{3}{|l|}{ After 1 month } \\
\hline 58 & $37(63.8 \%)$ & $21(36.2 \%)$ \\
\hline \multicolumn{3}{|l|}{ After 6 months } \\
\hline 49 & $31(63.3 \%)$ & $18(36.7 \%)$ \\
\hline
\end{tabular}

All the data are in total number and percent.

\section{Discussion}

Cannon and Epstein ${ }^{11,22}$ have proposed that dysfunction of small intramural pre-arteriolar coronary arteries might be the cause of the reduced flow reserve in patients with chest pain and normal coronary arteries. It is worth noting that in the absence of atherosclerotic disease of large epicardial arteries, almost all coronary resistance is located in the microcirculation. According to Chilian et al, ${ }^{23}$ a significant proportion (40-50\%) of total coronary resistance resides in arterioles greater than $100 \mu \mathrm{m}$. Furthermore, there is evidence for adrenergically mediated vasoregulation in coronary arterioles with a resting diameter greater than $100 \mu \mathrm{m}$ in which the presence of both $\alpha-1$ and $\alpha-2$ adrenergic receptors have been demonstrated. ${ }^{26}$
In this study the majority of the study population was comprised of women. All of the subjects were having typical anginal pectoris but most of them having normal coronary angiogram. Data from the WISE study 25 indicate that typical vs. atypical angina does not discriminate between obstructive and non-obstructive coronary disease in a population of women undergoing coronary angiography. Women with angina and normal angiograms may present with symptoms of both stable and unstable angina. The majority of patients seem to be between these two extremes, with a variable prevalence of the two types of symptoms.

Opherk et. al. ${ }^{26}$ first reported the finding of reduced coronary flow reserve in patients with angina and "normal" angiograms using the argon washout method. Several investigators using different techniques, such as coronary sinus thermodilution, positron emission tomography, and intracoronary Doppler velocity, have subsequently confirmed this finding. ${ }^{27-29}$ More recent studies addressed this issue calculating myocardial perfusion by magnetic resonance imaging. 30,31 Approximately $25 \%$ of the population of patients with angina and "normal" or near-normal angiograms had an abnormally reduced flow reserve using this technique. ${ }^{31}$ Gated single-photon emission computed tomography, ${ }^{31}$ and positron emission tomography ${ }^{29}$ can also detect abnormal flow reserve patterns. The prevalence of vascular dysfunction by coronary flow assessment, ${ }^{29} \mathrm{sin}$ gle photon emission computed tomography, ${ }^{31}$ or positron emission tomography ${ }^{28}$ consistently demonstrate abnormalities in $50 \%$ to $60 \%$ of women with "normal" or near-normal angiograms, suggesting that vascular dysfunction is common in this population. However we did not apply these methods to find out abnormal flow reserve in our study population.

All of the subjects in this study were prescribed beta blockers and nitrate together with aspirin and atorvastatin. Around 36\% subjects were benefited with regimen where as $63 \%$ subjects remained symptomatic. During the six months follow up around $16 \%$ cases were dropped out and never returned for follow up. We are not considering them symptom free; they may be searching some holistic approach or alternate medicine. Observational evidence does not support the widespread use of calcium antagonists in patients with "normal" angiograms because they seem to do little to prevent chest pain during daily life in these patients. ${ }^{32-34}$ Nitrates are referred to be of help in some patients but not in others. The placebo effect of nitrates cannot be ruled out. $\beta$ Blockers have been shown to be highly effective for reduction of chest pain episodes during daily life. ${ }^{33}$ There are several potential mechanisms by which $\beta$ blockers may act in reducing chest pain recurrences. They may counteract the pro-ischemic effects of increased adrenergic tone or may 
simply reduce myocardial oxygen demand. $\beta$ Blockers are endothelium-dependent vasodilators as well. ${ }^{35}$ The proven benefit of exercise training in this population suggests that mechanism of adrenergic modulation plays a role. ${ }^{36}$

In conclusion patients with angina but normal or nonobstructive coronary angiograms have traditionally been reassured that they do not have heart disease, but many of these patients have persistence of symptoms, are repeatedly hospitalized. Uncertainty about the mechanism of the symptoms and treatment efficacy can potentially lead to continuation of symptoms, difficulties in management, and neglect of atherosclerotic cardiac risk factor treatment.

\section{Reference}

1. Proudfit WL, Shirey EK, Sones FM Jr. Selective cine coronary arteriography: correlation with clinical findings in 1,000 patients. Circulation. 1966;33:901-10

2. Mahrer PR, Eshoo N. Outpatient cardiac catheterization and coronary angiography. Cathet Cardiovasc Diagn. $1981 ; 7: 355-60$

3. Coronary artery surgery study (CASS): a randomized trial of coronary artery bypass surgery-survival data. Circulation. 1983;68:939-50

4. Phibbs B, Fleming T, Ewy GA, et al. Frequency of normal coronary arteriograms in three academic medical centers and one community hospital. Am J Cardiol. 1988;62:472-74

5. Geltman EM, Henes CG, Senneff MJ, Sobel BE, Bergmann SR. Increased myocardial perfusion at rest and diminished perfusion reserve in patients with angina and angiographically normal coronary arteries. J Am Coll Cardiol. 1990; 16:586-95

6. Botker HE, Sonne HS, Bagger JP, Nielsen TT. Impact of impaired coronary flow reserve and insulin resistance on myocardial energy metabolism in patients with syndrome X. Am J Cardiol. 1997;79:1615-22

7. Reis SE, Holubkov R, Conrad Smith AJ, et al. Coronary microvascular dysfunction is highly prevalent in women with chest pain in the absence of coronary artery disease: results from the NHLBI WISE study. Am Heart J. 2001;141: 735-41

8. Kemp HG, Kronmal RA, Vlietstra RE, Frye RL. Seven-year survival of patients with normal or near normal coronary arteriograms: A CASS registry study. J Am Coll Cardiol 1986, $7: 479-83$

9. Kemp HG. Left ventricular function in patients with the anginal syndrome and normal coronary arteriograms. Am J Cardiol 1973, 32:375-76

10. Kaski JC, Crea F, Nihoyannopoulos P, Hackett D, Maseri A. Transient myocardial ischemia during daily life in patients with syndrome X. Am J Cardiol 1986, 58:1242-47

11. Cannon RO, Epstein SE. Microvascular angina as a cause of chest pain with angiographically normal coronary arteries. Am J Cardiol 1988, 61:1338-43
12. Cannon RO III, Watson RM, Rosing DR, Epstein SE. Angina caused by reduced vasodilator reserve of the small coronary arteries. J Am Coll Cardiol 1983, 1:1359-73

13. Bellamy MF, Goodfellow J, Tweddel AC, Dunstan FDJ, Lewis MJ, Henderson AH. Syndrome X and endothelial dysfunction. Cardiovasc Res 1998, 40:410-17

14. Maseri A, Crea F, Kaski JC, Crake T. Mechanisms of angina pectoris in syndrome X. J Am Coll Cardiol 1991, 17:499-06

15. Arbogast R, Bourassa MG. Myocardial function during atrial pacing in patients with angina pectoris and normal coronary arteriograms: comparisons with patients having significant coronary artery disease. Am J Cardiol 1973, 32:257-63

16. Boudoulas H, Cobb TC, Leighton RF, Wilt SM. Myocardial lactate production in patients with anginalike chest pain and angiographically normal coronary arteries and left ventricle. Am J Cardiol 1974, 34:501-05

17. Opherk D, Zebe H, Weihe E, Mall G, Durr C, Gravert B, Mehmel HC, Schwarz F, Kubler W. Reduced coronary dilatory capacity and ultrastructural changes of the myocardium in patients with angina pectoris but normal coronary arteriograms. Circulation 1981, 63:817-25

18. Greenberg MA, Grose RM, Neuburger N, Silverman R, Strain JE, Cohen MV. Impaired coronary vasodilator responsiveness as a cause of lactate production during pacinginduced ischaemia in patients with angina pectoris and normal coronary arteries. J Am Coll Cardiol 1987, 9:743-51

19. Opherk D, Schuler G, Wetterauer K, Manthey J, Schwarz F, Kubler W. Four-year follow-up study in patients with angina pectoris and normal coronary arteriograms ("syndrome $\mathrm{X}$ "). Circulation 1989, 80:1610-16

20. Kaski JC, Elliot PM. Angina pectoris and normal coronary arteriograms. Clinical presentation and hemodynamic characteristics. Am J Cardiol 1995, 76:35-42

21. Pasternak RC, Thibault GE, Savoia M, DeSanctis RW, Hutter AM Jr. Chest pain with angiographically insignificant coronary arterial obstruction: clinical presentation and long-term follow-up. Am J Med. 1980;68:813-17

22. Epstein SE, Cannon RO. Site of increased resistance to coronary flow in patients with angina pectoris and normal epicardial coronary arteries. J Am Coll Cardiol 1986;8:459-46

23. Chilian WM, Eastmam CL, Layne SM, Marcus ML. Small vessel phenomena in the coronary microcirculation: Phasic intra-myocardial perfusion and coronary microvascular dynamics. Prog Cardiovasc Dis 1988;31:17-38

24. Heusch G. a-Adrenergic mechanisms in myocardial ischemia. Circulation 1990;81: 1-13

25. Johnson BD, Shaw LJ, Buchthal SD. Prognosis in women with myocardial ischemia in the absence of obstructive coronary disease: results from the National Institutes of HealthNational Heart, Lung, and Blood Institute-sponsored Women's Ischemia Syndrome Evaluation (WISE). Circulation. 2004;109:2993- 99 
26. Opherk D, Mall G, Zebe H, et al. Reduction of coronary reserve: a mechanism for angina pectoris in patients with arterial hypertension and normal coronary arteries. Circulation. 1984;69:1-7

27. Bugiardini R, Pozzati A, Ottani F, Morgagni GL, Puddu P. Vasotonic angina: a spectrum of ischemic syndromes involving functional abnormalities of the epicardial and microvascular coronary circulation. J Am Coll Cardiol. 1993;22:41725

28. Reis SE, Holubkov R, Conrad Smith AJ, et al. Coronary microvascular dysfunction is highly prevalent in women with chest pain in the absence of coronary artery disease: results from the NHLBI WISE study. Am Heart J. 2001;141:735-41

29. Reis SE, Holubkov R, Lee JS, et al. Coronary flow velocity response to adenosine characterizes coronary microvascular function in women with chest pain and no obstructive coronary disease: results from the pilot phase of the Women's Ischemia Syndrome Evaluation (WISE) study. J Am Coll Cardiol. 1999;33:1469- 75

30. Panting JR, Gatehouse PD, Yang GZ, et al. Abnormal subendocardial perfusion in cardiac syndrome $\mathrm{X}$ detected by cardiovascular magnetic resonance imaging. $N$ Engl $\mathrm{J} \mathrm{Med}$. 2002;346:1948-53
31. Doyle M, Fuisz A, Kortright E, et al. The impact of myocardial flow reserve on the detection of coronary artery disease by perfusion imaging methods: an NHLBI WISE study. $J$ Cardiovasc Magn Reson. 2003; 5:475-85

32. Pizzi C, Manfrini O, Fontana F, Bugiardini R. Angiotensinconverting enzyme inhibitors and 3-hydroxy- 3-methylglutaryl coenzyme a reductase in cardiac syndrome X: role of superoxide dismutase activity. Circulation. 2004;109:53-58

33. Lanza GA, Colonna G, Pasceri V, Maseri A. Atenolol versus amlodipine versus isosorbide-5- mononitrate on anginal symptoms in syndrome X. Am J Cardiol. 1999;84:854-56

34. Masumoto A, Mohri M, Takeshita A. Three-year follow-up of the Japanese patients with microvascular angina attributable to coronary microvascular spasm. Int J Cardiol. 2001;81:15156

35. Kalinowski L, Dobrucki LW, Szczepanska- Konkel M, et al. Third-generation beta-blockers stimulate nitric oxide release from endothelial cells through ATP efflux: a novel mechanism for antihypertensive action. Circulation. 2003;107:2747-52

36. Eriksson BE, Tyni-Lenne R, Svedenhag J, et al. Physical training in Syndrome X: physical training counteracts deconditioning and pain in Syndrome X. J Am Coll Cardiol. 2000;36:1619-25 